\title{
Subclavian Perivascular Technique of Brachial Plexus Anaesthesia
}

\author{
Dr Chethanananda T N (Asso. prof.), Dr Shashank M R, Dr Swathi S, \\ Dr Ramesh M C
}

\begin{abstract}
Various approaches to brachial plexus block have been described. Among the supraclavicular approaches even the procedure itself varies. With earlier techniques the exact site for insertion of needle was determined using visual topographic landmarks (1 cm above the midpoint of clavicle) ${ }^{1}$ whereas with more recent technique, palpable landmarks( the scalene muscle and the interscalene groove) have been utilised ${ }^{2}$. In our study the subclavian perivascular technique of brachial plexus block was conducted in a tertiary level hospital. It was prospective non randomized open level study from 2011 to 2013 which includes 66 patients of both sexes between the age group of 20 to 50 years (ASA grading 1 and 2 patients) undergoing elective upper limb surgeries.

The onset and duration of sensory and motor block, need for supplement anaesthesia were observed. Success and complication rate were calculated in percentage. Average onset and duration of sensory and motor block was calculated as mean $\pm S D$ and percentage out of 66 patients, 60 patients (90.90\%) have got successful block with no significant complications
\end{abstract}

Keywords: Brachial plexus block, Supraclavicular block, Subclavian Perivascular approach

\section{Introduction :}

So many technique for blocking brachial plexus at different levels were established to provide anaesthesia for surgery on upper extremities. The level of brachial plexus block and the technique selected depends upon the site of surgical interventions and also on the experience of the anaesthesiologist. Furthermore when one of the supraclavicular techniques is chosen even the procedure itself varies.

The subclavian perivascular technique of brachial plexus block as first described by Winnie and Collins in $1964^{2}$ has proven to be a valuable method of providing anaesthesia for the lower arm, forearm and hand surgeries. There are several features of traditional 'supraclavicular block' technique that can be criticized on the anatomical basis alone. Applying the perivascular concept to the supraclavicular approach obviates the undesirable features of the classic technique.

\section{Method :}

66 patients of ASA grade I and II scheduled for surgery on the upper limb were selected and informed written consent was taken. Exclusion criteria includes patient refusal, coagulopathies, infection at injection site. IV access established with $18 \mathrm{G}$ cannula and light sedation with IV midazolam $0.01-0.03 \mathrm{mg} / \mathrm{kg}$ given. Standard monitors (NIBP, ECG, SPO2) were applied. All the patients were made to lie in supine position with head turned to opposite side and the arm pulled down gently and a small pillow is placed below the shoulder to make the field prominent.

Patient is asked to elevate the head slightly to bring the clavicular head of sternocleidomastoid muscle in to prominence and the index finger is placed behind the muscle. The elevated head is relaxed and the palpating finger is rolled laterally across the belly of anterior scalene muscle until the interscalene groove is felt. Then the finger is moved inferiorly in the groove until the subclavian artery pulsation is felt. With the fingers still on the artery a $1-1 \frac{1}{2}$ inch $21 \mathrm{G}$ needle is inserted above the point in a direction that is directed caudal but not medial or dorsal. The direction of the needle will be dorsally tangential to subclavian artery in the longest dimension of interscalene space. 


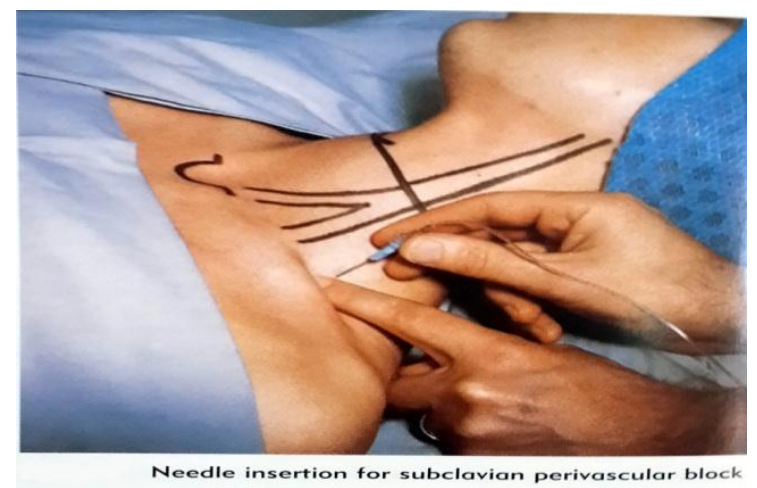

The arterial pulse (or the lowest point of the interscalene groove) is identified \& the needle is inserted immediately above the palpating finger between the scalene muscles(as shown in fig.)

Advance the needle slowly to elicit paresthesia as per the dictum of Moore, "No paresthesia, No anaesthesia"3. Once paresthesia is evoked $30 \mathrm{ml}$ of $1.5 \%$ lignocaine with adrenaline was injected and the intercostobrachial nerve is blocked to facilitate tourniquet application.

\section{Assessment Of Sensory And Motor Block}

Soon after the drug deposition in to perivascular space the successfulness of the block is assessed by absence of cold perception and loss of response to the pin prick (sensory block) and the motor block is assessed by paresis of limb and the inability to lift or abduct the forearm.

The onset of sensory and motor block were observed every $2 \mathrm{mins}$, and the time of first call from patient for supplemental analgesia and the time of hand lifting against gravity noted at 15 mins interval after surgery.

Inadequate analgesia was considered in patient requiring $>50 \mathrm{mg}$ of injection propofol for continuation of surgery or patients requiring general anaesthesia. Successfulness of block and complication rates were calculated in percentage. Average onset and duration of sensory and motor block were calculated as mean $\pm \mathrm{SD}$ and percentage with the software windows office excel ${ }^{\circledR}$

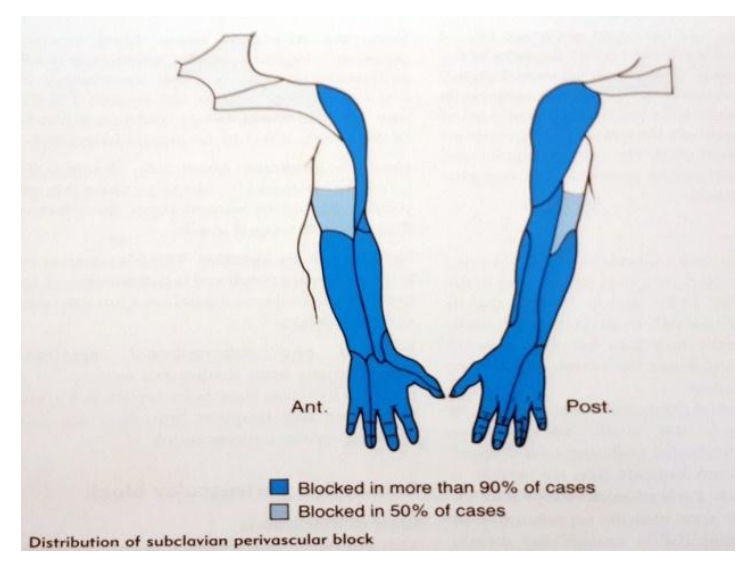

\section{Results}

66 patients both male and female between the age group 20-50 yrs who undergoing surgeries received this block ( 32 cases with fracture of forearm, 10 cases fracture lateral condyle humerus, 8 cases fracture lower end of humerus lower one third and 18 cases of hand surgeries). In 60 out of 66 patients the block was successful in providing analgesia and 49 patients did not require any supplemental medications but 11 patients required injection propofol $50 \mathrm{mg}$ or less for skin incision only. 6 patients (9\%) required more than $50 \mathrm{mg}$ of injection propofol or general anaesthesia in addition to block to proceed with surgery.

\section{Sensory Block:}

$>$ The average time for complete analgesia was $11.725 \pm 2.01$ (mean $\pm \mathrm{SD}$ ) minutes

$>$ Duration of analgesia was $2.65 \pm 0.63$ (mean $\pm \mathrm{SD}$ ) $\mathrm{hrs}$ as observed by first call of patient for Motor Block supplemental analgesia

$>$ The average time for motor block was $15.75 \pm 3.18$ (mean $\pm \mathrm{SD}$ ) minutes

$>$ Average duration of motor block was $107.5 \pm 3.53($ mean $\pm \mathrm{SD}$ ) minutes 


\section{Complications}

Rupture of subclavian vessel were encountered in 15 patients but block could be performed by reposition of the needle without hematoma formation. No other complications noted

\section{Discussion}

There are various approaches to brachial plexus block viz supraclavicular, interscalene, infraclavicular, axillary and transcalene ${ }^{1}$ routes. In search of high success rate and less complications supraclavicular approach is technically easy with less serious complications.

'Supraclavicular block' technique that can be criticized on an anatomical basis alone; first, the site of needle insertion is usually made $1 \mathrm{~cm}$ above the midpoint of clavicle, and it has been shown by actual dissection that this point is frequently does not lie over the first rib as described ${ }^{2}$. Since the later is supposed to act as a "back stop" to protect the cupola of lung from penetration by the exploring needle, it is remarkable that the incidence of the pneumothorax is not even higher than $0.5-0.6 \%$ reported in the literature ${ }^{3}$. Secondly, the direction of the needle is described as "mesiad, caudad and dorsad", and a consideration of anatomy of "brachial plexus" sheath presented above would seem to make this illogical. Since the subclavian perivascular space is bounded by the anterior and middle scalene muscles, it is described very narrow in its anteroposterior direction. Thus the direction of needle insertion advocated in the 'supraclavicular technique' results in needle crossing the space in its narrowest diameter. Therefore, even the slightest movement during the injection may cause the needle to leave the space, and with multiple injections this possibility is increased even more. Thirdly, the needle is usually 'walked along the rib' to obtain consecutive paresthesia of various distributions, with an injection of anaesthetic being made each time a paresthesia is elicited. This would also appear to be quite illogical, as the trunks lie one atop the other vertically as they cross the $1^{\text {st }}$ rib and not one behind the other horizontally as depicted in many texts ${ }^{4}$.

As a result of all above, the classic technique results in use of large volume of anaesthetic solutions leading to complications. It is no wonder that Adriani wrote, "when (we) use the supraclavicular route, (we) do so with a certain amount of Fear and trepidation"5.

In the present study the use of short needle and single injection not only tend to improve the incidence of satisfactory results, but also minimize the possibility of pneumothorax. Since the direction of needle insertion is parallel to the borders of the scalene muscles and since these muscle inserts on the $1^{\text {st }}$ rib, the position of the rib and vessel is located more precisely with this technique than any other, although in this technique, in the vast majority of cases paresthesia are obtained before the rib has been contacted.

The advantage of this technique include a fact that high level of anaesthesia may be achieved with a relatively small volume of anaesthetic solution $(30 \mathrm{ml})$, so if large doses $(40 \mathrm{ml})$ of anaesthetics are contraindicated, no supplemental blocks are necessary to limit the volume. This technique also allows the block to be accomplished without moving the painful extremity or shoulder, intravenous injection is mostly unlikely and inadvertent subarachnoid and epidural injection is virtually impossible.

Kumar et al, and Ross reported epidural and subarachnoid blockade due to widespread distribution of anaesthetic agents with interscalene route ${ }^{6,7}$.

Although pneumothorax, the phrenic nerve and recurrent laryngeal nerve block are not really impossible, if the technique is carried out precisely as described, the possibility is extremely remote indeed. Leonard and Pepper injected local anaesthetic agent by Murphy's supraclavicular route but had $60 \%$ of pneumothorax ${ }^{8}$. The incidence of pneumothorax was $1.5 \%$ as described by Moore ${ }^{9}$.

A minor disadvantage lies in the need to elicit paresthesia which may be less pleasant for the patient but paresthesia almost guarantees anaesthesia as per the dictum of Moore 'no paresthesia, no anaesthesia' ${ }^{13}$.

In subclavian perivascular approach the needle will be dorsally tangential to subclavian artery in the longest dimension of the interscalene space. The needle is advanced slowly, and if superior trunk is not encountered, the middle will be; if middle is not encountered, the inferior will be; and if none of these are encountered, the needle will impinge on the $1^{\text {st }}$ rib which is very rare and usually paresthesia is evoked after advancing the needle a short distance.

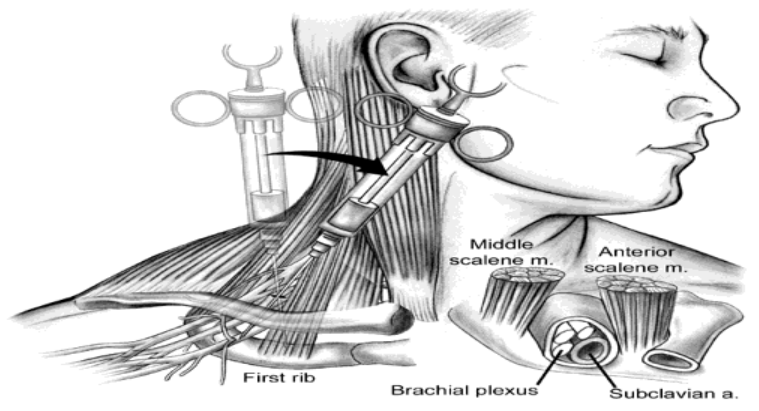




\section{Conclusion}

It can be concluded that the subclavian perivascular brachial plexus block consistently provide an effective block for the surgery of the upper extremity. At the site of injection with this technique, the plexus is reduced to its smallest volume, which explains in great part of success obtained with this block. Occasionally the subclavian artery prevent solutions spreading to inferior trunk and the block may be deficient in $\mathrm{C}_{8} \mathrm{~T}_{1}$ distribution, but this can be uncommon if a sufficient volume $(30 \mathrm{ml})$ is injected. If the technique of block is carried out precisely as described there will be a remote chance of any complication.

\section{References}

[1] Kothari D. Supraclavicular brachial plexus block: A New approach. IJA 2003;47:2878

[2] Winnie AP, Colline VJ. The subclavian perivascular technique of brachial plexus anaesthesia. Anesthesiology 1964;25:353-63

[3] Moore DC. Regional Anesthesia. Springfield, IL: Charles C. Thomas, 1953;241

[4] Eriksson E: in illustrated handbook of local anaesthesia, p.75, edited by Eriksson E; year book publishers, Inc., Chicago 1969

[5] Accardo NJ and Adriani J: Brachial plexus block. A simplified technique using axillary route. South med j 920-923,1949

[6] Leonard B; Papper EM. A comparison of supraclavicular and axillary technique for brachial plexus block. Anesthesiology $1961 ; 22: 2269$

[7] Moore DC. Supraclavicular approach for block of the brachial plexus. In ; Thomas CC, editor. Regional block: A handbook for use in the clinical practice of medicine and surgery $4^{\text {th }}$ Ed. Springfield, Illinois, USA.1965.p.221-42

[8] Kumar A, Battit GE, Froese AB, Long MC. Bilateral cervical and thoracic epidural blockade complicating interscalene brachial plexus block: Report of two cases. Anaesthesiology1971;35:6502

[9] Ross S, Scarborough CD. Total spinal anaesthesia following brachial plexus block. Anesthesiology 1973;39:458 